Research Article

\title{
Integrated Interactive Tutorial for Dental Students to Teach Medical Subjects - An Innovative Approach to Effective Learning
}

\author{
Neeta Kumar', Anita Sharma ${ }^{2}$, Sazina Muzammil ${ }^{3}, \underline{\text { Mohammad Saleem }}^{4}$ \\ ${ }^{1}$ Professor, ${ }^{4}$ Associate Professor, Department of General Pathology, Faculty of Dentistry, Jamia Millia Islamia, New Delhi, \\ India. \\ 2,3Professor, Department of Physiology, Faculty of Dentistry, Jamia Millia Islamia, New Delhi, India.
}

DOI: https://doi.org/10.24321/2455.9199.201904

\section{I $\quad \begin{array}{lllll}\mathbf{N} & \mathbf{F} & \mathbf{O}\end{array}$}

\section{Corresponding Author:}

Mohammad Saleem, Department of General Pathology, Faculty of Dentistry, Jamia Millia Islamia, New Delhi, India.

E-mail Id:

msaleem1@jmi.ac.in

Orcid Id:

https://orcid.org/0000-0002-6207-7818

How to cite this article:

Kumar N, Sharma A, Muzammil S et al. Integrated Interactive Tutorial for Dental Students to Teach Medical Subjects - An Innovative Approach to Effective Learning. Int J HealthCare Edu \& Med Inform 2019; 6(1): 10-15.

Date of Submission: 2019-05-14

Date of Acceptance: 2019-07-11

\section{$\begin{array}{llllllll}\mathbf{A} & \mathbf{B} & \mathbf{S} & \mathbf{T} & \mathbf{R} & \mathbf{A} & \mathbf{C} & \mathbf{T}\end{array}$}

Background: The students in medical and dental courses are usually focused on achieving good grades in the examinations. They tend to forget the knowledge gained in pre and paraclinical subjects and hence application of knowledge to the practical life situations suffers. There is a need to change this attitude of "learning only for exams" to "learning for applying the knowledge" for good care of the patients. It is well known that integrated teaching leads to better understanding of the topic than the traditional teaching.

Aims and Objectives: Aim was to promote active self learning and develop skills of integrating knowledge. The objectives were to: (1) Introduce the integrated interactive learning method through two departments, (2) To obtain feedback from the students and faculty.

Methods: An innovative approach of integrated interactive tutorial was tried among second year students of Bachelor of Dental Surgery (BDS) course. Students were asked to prepare the Physiology and Pathology of a common clinical condition over a week's time. During the session, students asked questions on physiology and pathology of that condition from each other. The teachers acted only as facilitators. These sessions were conducted for three consecutive years. After each session, the authors obtained the feedback of students and faculty on their satisfaction and learning experience of this alternative learning strategy.

Results: Majority of students felt that this method of learning helped to develop reasoning skills, motivated them towards active self learning and leads to better and deeper understanding of the topic.

Conclusion: Integrated interactive tutorial proves to be an easy and learner centred approach to effective learning.

Keywords: Self Learning, Active Learning, Interactive, Integrated, Tutorial, Dental, Medical, Education 


\section{Introduction}

Undergraduate medical and dental courses are taught over a span of 5 years. The teaching curriculum follows a "building block system" where each subject is taught in its own block of time laying foundation for the other subjects which are taught in later years. This fragmented approach leads to compartmentalization of disease process and does not give them a comprehensive picture. There is some overlap in different lectures and unnecessary repetition occurs which is not a good use of teachers' time.

The students are expected to not only remember what they learnt in earlier years of teaching of preclinical and paraclinical subjects but also integrate that knowledge with clinical subjects and apply it during their clinical duties subsequently. However, the students have a tendency to forget and often do not become proficient enough to integrate and apply knowledge to the practical life situations though they may achieve good grades in the examinations. We as teachers in medical and dental colleges need to change this attitude of "learning only for exams" to "learning for applying the knowledge" for good care of the patients.

Knowing that active self learning is the best for long term shelf life of knowledge, previously the authors tried intraclass interactive tutorials and quiz as innovative methods of active self learning and found them very effective. ${ }^{1-2}$ The experience of integrated teaching in some medical and dental colleges in India and abroad has shown that integrated teaching leads to better understanding of the subject than the traditional teaching. ${ }^{3-6}$ It promotes integrated thinking and helps develop holistic outlook towards disease conditions among students.

The present study is based on another innovative method of active self learning "Integrated Intraclass Interactive Tutorial". This is an advancement of the previous method of intraclass interactive tutorial combined with the emphasis on integrating knowledge of a particular disease condition from two or more subjects. The aim was to promote active self learning and develop skills of integrating knowledge of different subjects to learn about a disease condition in undergraduate dental students. The objectives were to:

- Introduce the integrated interactive learning method through two departments.

- To obtain feedback from the students and faculty on feasibility of integrated interactive learning of medical subjects in dental curriculum.

\section{Materials and Methods}

A cross sectional interventional study was planned for second year dental students in our college. Common clinical conditions such as anemia, hypertension were identified as topics for Integrated interactive tutorials according to their importance for dental course.
A questionnaire was designed to collect feedback from students. The questions were framed to study feasibility of this learning method by collecting data on perceived benefits and challenges faced by them. The questionnaire was pretested on 10 students and proper changes were made after pretesting the questionnaire. This was self administered questionnaire with both open ended and closed questions. The students were explained orally the purpose of the study and asked to fill the questionnaire anonymously and voluntarily. No identification data was included in the questionnaire. Those students who consented were asked to fill the questionnaire. Four faculty members of Physiology and Pathology Departments also provided feedback of their perception on benefits and challenges.

Second Year Students of Bachelor of Dentistry (BDS) course in our college were informed about the topic and were asked to prepare the Physiology and Pathology of that condition over a week's time. During the tutorial the class was divided into two groups A and B. Students of Group A asked questions from Physiology of the clinical condition to the Group B students. Then the Group B put questions to Group A from Pathology of that condition. The integrated interactive tutorials were conducted in routine teaching period of one hour on two occasions for three consecutive years (2016-2018).

The teachers acted only as facilitators intervening only when students had difficulty to frame the questions properly or were not able to explain or understand some concepts. In the end the students filled a questionnaire to provide their feedback on this method of learning. The data obtained from questionnaire was filled in excel sheet and expressed as percentages.

\section{Result}

The questionnaire was given to 138 students in three sessions. Total of 134 students provided feedback.

Both quantitative and qualitative data from the questionnaire on 3 point scale are summarized in Table 1.

\section{Benefits to the Students}

A majority (91\%) enjoyed the session more than the lectures and agreed that it helped them to understand the topic better than self reading. They were motivated (Figure1) to prepare for it and $58 \%$ were encouraged to do extra reading out of which $51 \%$ preferred advanced text books, $44 \%$ took the help of internet while $5 \%$ referred to journals.

Most of the students (86\%) felt that this method of learning fulfils the purpose of integrated teaching; i.e. this tutorial helped them to develop reasoning skills, Figure 2 . The students developed enhanced ability to integrate the relation between physiology and pathology of common 
clinical conditions with increased in-depth understanding of the topic. Correlation of pathophysiology with clinical picture became easy for them. Presence of teachers from both subjects facilitated this process that helped in clarifying some concepts and reasoning.

These tutorials generated interest and curiosity about the topic and motivated the $91 \%$ students to learn and know advanced information on the topic by self learning. Majority of the students asserted that such tutorials will improve their communication skills (95\%) and help them in viva voce examination (89.6\%), Figure 2.

Overall this was an effective approach to develop skills of critical reasoning and collaboration among students. Students even suggested that pharmacology should also be integrated with physiology and pathology of a particular condition. Many more topics for such tutorials were suggested by students and they also wanted to include clinical problems in such sessions as problem based learning. Some wanted more of such sessions after every topic instead of class test.

\section{Feedback by the Teachers}

The study promoted interdepartmental cross discipline collaboration and better students' linkages. This will help to avoid repetition of background knowledge in second year lectures. The faculty observed that communication skills and confidence of shy students also improved. This could benefit them in viva voce examination which is an important part of their examination. It will also benefit them when later in their career as healthcare providers they need to communicate with patients, care givers, relatives and peers in scientific community.

The study provided an opportunity to the teachers to get a break from routine monotonous didactic lectures. It also gives a professional satisfaction to see enhanced learning of students on their active participation in the tutorials.

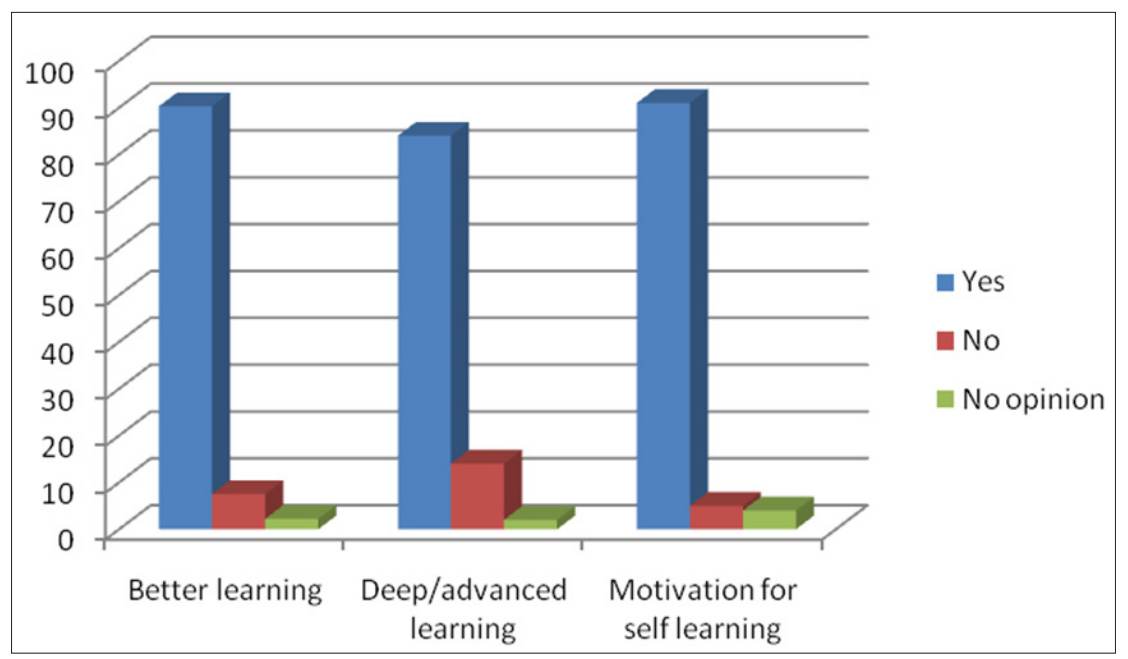

Figure I.Students' response on effectiveness of integrated interactive tutorial on learning process

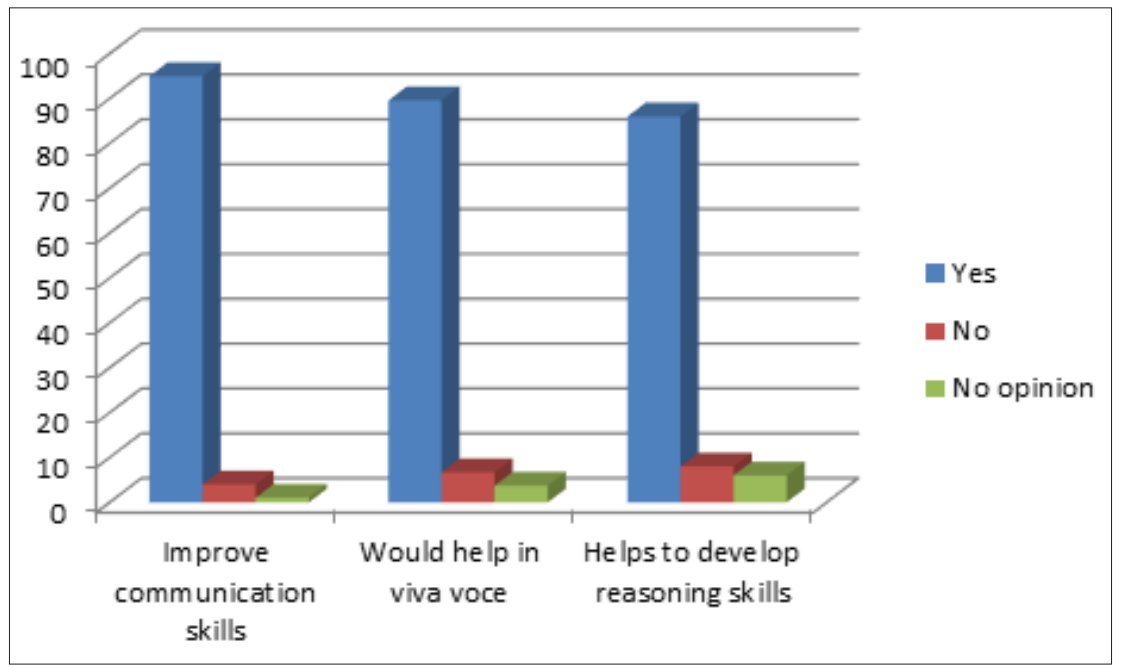

Figure 2.Students' response on effectiveness of integrated interactive tutorial on communication and reasoning skills 
Table I.Students' feedback from the questionnaire

\begin{tabular}{|c|c|c|c|c|}
\hline $\begin{array}{l}\text { S. } \\
\text { No. }\end{array}$ & Questions & Yes N (\%) & No $N(\%)$ & $\begin{array}{l}\text { No Opinion } \\
\quad \mathbf{N}(\%)\end{array}$ \\
\hline 1. & $\begin{array}{l}\text { Do you find Interactive Integrated Tutorial (IIT) } \\
\text { more interesting and more enjoyable than didactic } \\
\text { lectures? }\end{array}$ & $122(91)$ & $9(7)$ & $3(2)$ \\
\hline 2. & $\begin{array}{l}\text { Do you think participation in such tutorials would } \\
\text { improve your communication skills }\end{array}$ & $127(95)$ & $5(4)$ & $2(1)$ \\
\hline 3. & $\begin{array}{l}\text { Do you think such tutorials would help you to } \\
\text { perform better in viva voce examination? }\end{array}$ & $120(89.6)$ & $9(6.7)$ & $5(3.7)$ \\
\hline 4. & $\begin{array}{l}\text { Do you think learning to make questions helps you } \\
\text { to learn and understand the topic better? }\end{array}$ & $121(90.3)$ & $10(7.5)$ & $3(2.2)$ \\
\hline 5. & $\begin{array}{l}\text { Do you think this tutorial will motivate you to do } \\
\text { self learning? }\end{array}$ & $122(91)$ & $7(5)$ & $5(4)$ \\
\hline 6. & $\begin{array}{l}\text { Do you think it will help/contribute to deep } \\
\text { learning (more advance knowledge) about the } \\
\text { topic? }\end{array}$ & $112(84)$ & $19(14)$ & $3(2)$ \\
\hline 7. & $\begin{array}{l}\text { Do you think this tutorial helped those students } \\
\text { who were not prepared with the topic }\end{array}$ & $114(85)$ & $12(9)$ & $8(6)$ \\
\hline 8. & $\begin{array}{l}\text { Do you think this tutorial helps you to correlate } \\
\text { physiology and pathology of a disease? }\end{array}$ & $121(90)$ & $8(6)$ & $5(4)$ \\
\hline 9. & $\begin{array}{l}\text { Do you think this tutorial helps you to develop } \\
\text { reasoning skills? }\end{array}$ & $115(86)$ & $11(8)$ & $8(6)$ \\
\hline \multirow{4}{*}{10.} & \multirow{4}{*}{$\begin{array}{l}\text { Did you consult sources other than text book while } \\
\text { preparing for this tutorial? If yes, please specify! }\end{array}$} & $78(58)$ & \multirow{4}{*}{$43(32)$} & \multirow{4}{*}{$13(10)$} \\
\hline & & Internet/Wikipedia: 34 (44) & & \\
\hline & & $\begin{array}{l}\text { Advanced text books: } 40 \\
\text { (51) }\end{array}$ & & \\
\hline & & Journals: 4(5) & & \\
\hline 11. & $\begin{array}{l}\text { Which is more useful- interactive tutorial or self } \\
\text { reading? }\end{array}$ & $\begin{array}{l}\text { Interactive Tutorial } \\
\quad 110 \text { (82) } \\
\text { *Both are useful: } 5 \text { (4) }\end{array}$ & $\begin{array}{l}\text { Self } \\
\text { reading } \\
16(12)\end{array}$ & $\begin{array}{l}\text { No opinion } \\
3(2)\end{array}$ \\
\hline 12. & $\begin{array}{l}\text { Would you like to have more integrated interactive } \\
\text { tutorials on different topics? }\end{array}$ & $123(92)$ & $7(5)$ & $4(3)$ \\
\hline \multirow{5}{*}{13.} & \multirow{5}{*}{$\begin{array}{l}\text { Did you face any challenges while preparing for } \\
\text { tutorial? If yes, please specify! }\end{array}$} & $106(79)$ & \multirow{5}{*}{$9(7)$} & \multirow{5}{*}{$19(14)$} \\
\hline & & $\begin{array}{l}\text { Preparing and framing } \\
\text { questions appropriately }\end{array}$ & & \\
\hline & & $\begin{array}{l}\text { Reading previous year } \\
\text { subject }\end{array}$ & & \\
\hline & & $\begin{array}{l}\text { Time consuming, as } \\
\text { extensive reading is needed }\end{array}$ & & \\
\hline & & $\begin{array}{l}\text { Better reading material } \\
\text { required }\end{array}$ & & \\
\hline
\end{tabular}




\begin{tabular}{|c|c|c|}
\hline 14. & $\begin{array}{c}\text { What are the comments/ suggestions to improve } \\
\text { this kind of learning activity? }\end{array}$ & $\begin{array}{l}\text { - Active participation of all the students should be } \\
\text { there } \\
\text { - Students should come with full preparation } \\
\text { - Make rounds for types of questions. Such as, } \\
\text { round A for one word answers and round B for } \\
\text { long answers } \\
\text { - Objective questions or Multiple choice questions } \\
\text { - } \quad \text { Mould also be asked } \\
\text { - Healthy competition should be there } \\
\text { - Such Tutorials should be held time to time for all } \\
\text { important topics }\end{array}$ \\
\hline
\end{tabular}

\section{Challenges to the Students}

They had to prepare the topic by studying both subjects and had to spare extra time. Some of them could not frame appropriate questions. They tried to take help of books and internet to frame the questions and ended up making difficult and challenging questions to show off their knowledge though these questions may not be very relevant for second year course.

Some students did not participate in asking questions or answering their peers' questions and they appeared to be not prepared for the tutorial. Most of the students remained actively engaged throughout the tutorial and shy students were also encouraged to speak. Skills of preparing questions improved. Hesitation of answering in front of their peers decreased.

A particular topic could not be completed due to shortage of time. There were some overlapping questions or some questions were not framed properly and were not understood by their peers. Some questions were irrelevant or difficult. The students identified their deficiencies and could not understand some answers clearly and hence required help of the teacher.

\section{Challenges to the Teachers}

Teachers need to find extra time under pressure of course completion which is an extra work for the teachers. Departmental barriers have to be broken and lack of cooperation from other departments is feared. Teachers felt that some students tend to show off, bullying others, causing embarrassment to shy students. The teachers had to play an effective role in conflict management and promote respectful relationship by maintaining discipline and controlling teams and explain answers. They need to follow up with the weak students to encourage them to explore, solve problems and communicate.

\section{Suggestions to Improve}

Students suggested that these tutorials can be further improved if all students prepared well and participate. Some students thought if the questions were shared in advance, they can prepare the answers better. They did not like the idea of marks being given for their answers which was done in the first round. This was discontinued subsequently.

\section{Discussion}

This method of learning by integrated tutorial in our study appeared to be an easy approach to effective learning. The continuous enthusiasm of students for such sessions shows that it's a fun way of learning which is always better than the dull and drab way of studying alone. According to Haranath ${ }^{3}$ in the pyramid of average learning retention rates in different teaching learning methods are as follows: lectures $5 \%$, reading $10 \%$, audio-visual $20 \%$, demonstration $30 \%$, group discussion $50 \%$, practice by doing $75 \%$ and teaching others $90 \%$.

This method basically involved learning from peers. Whatever students are capable of achieving on their own is further augmented with the assistance of other students who may be more knowledgeable, have different strengths, abilities and interests. It is observed that students always understand better from their peers as most of the times they face the same difficulties, have the same level of understanding, and speak their own language and hence explain better. The importance of peer learning is very well explained by Boud $\mathrm{D}$ et al in their book. ${ }^{7}$ According to them, formalized peer learning can help students learn effectively. Some authors have described a "Reciprocal Peer Questioning Model" on similar lines. ${ }^{8}$

In our study the formalized peer learning is supervised by teachers and hence the results are even better. Johnson et al have explained in their book how college teachers can make use of cooperative learning to increase student achievement. According to the authors cooperative learning also helps create a positive relationship among students and helps them to adjust better in college. ${ }^{9}$ 
Curriculum integration usually involves both horizontal and vertical integration and is being widely used throughout the world. ${ }^{10}$ An integrated approach allows learners to explore, gather, process, refine and present information about topics they want to investigate without the constraints imposed by traditional subject barriers. ${ }^{5}$ The benefits of integrated learning include improved motivation, professional socialization, deep learning and it also prepares one for lifelong learning. ${ }^{11}$ Students make more real world connections in integrated classrooms and are also more actively engaged. ${ }^{6}$ Learning analytical skills through integrated teaching can improve the quality and value of the learning experience. ${ }^{4}$

Integrated approaches to teaching and learning are most effective when they respond to students' strengths, abilities and interests. These also enable learning across multiple domains. The best outcomes are achieved when all aspects of their development are stimulated including social, physical, intellectual, emotional and creative abilities. The students develop an attitude towards lifelong, selfdirected learning.

Students took a keen interest in such tutorials and showed a lot of enthusiasm. Instead of just consulting their regular text books they also gained knowledge from the internet and also like to consult journals. This helps in deep learning and improves their reasoning skills. The overwhelming response of the students was very encouraging for the teachers, motivating them to keep thinking of newer class room activities.

\section{Limitations of the Study}

The impact on students' performance in theory and viva voce was not evaluated due to cross-sectional design of the study.

\section{Conclusion}

1. Integrated interactive tutorial proved to be an easy approach for effective learning enjoyed by the students.

2. This enhanced students' confidence, communication and reasoning skills.

3. Students were motivated for active self learning.

\section{Conflict of Interest: None}

\section{References}

1. Sharma A, Ahmad T. Role of Intraclass Interactive Student Tutorial in Medical Teaching. Journal of Medical Erudite 2015; 3(1): 49-54.

2. Saleem M, Kumar N. Quiz in Medical Subjects for Active Self-Learning by Undergraduate Dental Students: A Pilot Study. Journal of Research in Medical Education and Ethics 2018; 8(3): 222-226.

3. Haranath P. Integrated teaching in medicine - Indian scene. Indian Journal of Pharmacology 2013; 45(1): 1-3.
4. Long P, Siemens G. Penetrating the Fog: Analytics in Learning and Education. EDUCAUSEreview [Internet]. 2011 September/October 12 [cited 2018 Oct 10]. Available from: https://er.educause.edu/ articles/2011/9/penetrating-the-fog-analytics-inlearning-and-education.

5. Pigdon K, Woolley M, (Eds). The Big picture: integrating children's learning. Armadale, Victoria: Eleanor Curtain Publishing; 1992.

6. Boyd S. Integrated Curriculum: Definition, Benefits \& Examples [video]. Chapter8/ Lesson27 [cited 2018 Oct 10]. Available from: https://study.com/academy/ lesson/integrated-curriculum-definition-benefitsexamples.html.

7. Boud D, Cohen R, Sampson J (Eds.). Peer Learning in Higher Education: Learning from and with Each Other. Sterling, VA: Stylus Publishing Inc; 2001.

8. King A. Reciprocal peer questioning: A strategy for teaching students how to learn from lectures. The Clearing House: A Journal of Educational Strategies, Issues and Ideas 1990; 64(2): 131-135.

9. Johnson DW, Johnson RT, Smith KA. Active learning: cooperation in the college class. Edina, MN: Interaction Book Company; 1998.

10. Rafique N. Importance of vertical integration in teaching and assessment of physiological concepts. Journal of Taibah University Medical Sciences 2014; 9(4): 282-288.

11. Bradley P, Mattick K. Integration of basic and clinical sciences - AMEE 2008, Peninsula College of Medicine and Dentistry, UK. Available from: https://amee.org/ getattachment/Conferences/AMEE-Past-Conferences/ AMEE-Conference-2008/Introduction-to-Medical- 